\title{
denúncias e pronúncias: estudos afroperspectivistas \\ sobre infâncias e educação das relações étnico-raciais
}

\author{
renato noguera ${ }^{1}$ \\ universidade federal rural do rio de janeiro, brasil \\ orcid id: http:/ / orcid.org/0000-0002-6609-9360
}

resumo

O horizonte dos desafios deste breve estudo afroperspectivista está na articulação entre educação das relações étnico-raciais e os estudos da infância. As questões geracionais da infância não estão dissociadas da racialização. Portanto, o racismo é um fenômeno que precisa ser enfrentado nos contextos infantis. Este ensaio faz algumas denúncias acerca de situações de racismo que afligem crianças no Brasil. Para além das denúncias que se fazem necessárias e incontornáveis. Este artigo-ensaio destaca o que aqui denominamos de pronúncias. Através das pronúncias postulamos que é importante propor caminhos antirracistas. A filosofia afroperspectivista opera através de uma trama na qual a Infância enquanto conceito filosófico - é a chave existencial e política para promoção da afrotopia. Levando em conta o debate feito pelo economista senegalês Felwine Sarr, a afrotopia é tomada como possibilidade real. Numa abordagem afroperspectivista, a conjectura é de que precisamos denegrir e infancializar a vida para construir um afrotopos. Um aspecto que merece destaque é a ideia de que o projeto Ocidental promove a adultidade, o que implica na colonização da vida e do mundo. A nossa hipótese é de que através da promoção da infância podemos ter as condições necessárias para sociedades antirracistas. No final do artigo-ensaio sugerimos um estatuto afroperspectivista da infância como indicador próativo de promoção de outras realidades.

palavras-chave: afroperspectividade; denúncias; étnico-raciais; infância; pronúncias.

\section{complaints and pronouncements: afro-perspectivist studies on childhood and education of ethnic-racial relations}

\section{abstract}

This brief Afroperspectivist study explores the articulation between the education of ethnicracial relations and childhood studies. The generational issues of childhood are not dissociated from racialization. Therefore, racism is a phenomenon that needs to be tackled in children's contexts. This essay makes some complaints about situations of racism that afflict children in Brazil, and offers what we call pronouncements. We postulate that it is important to propose anti-racist paths. Afro-perspectivist philosophy operates on the assumption that childhood - approached as a philosophical concept - is the existential and political key to the promotion of afrotopia, which the Senegalese economist Felwine Sarr understands as a real historical possibility. We argue that the Western project promotes adulthood, which implies the colonization of life and the world. Our hypothesis is that through the promotion of childhood we can create the necessary conditions for anti-racist societies, and offer an afro-perspectivist understanding of childhood as a proactive indicator of the possibility other realities.

keywords: afroperspectivism; anti-racism; childhoods; utopia.

\footnotetext{
${ }^{1}$ E-mail: renatonoguera@ymail.com
} 
denúncias e pronúncias: estudos afroperspectivistas sobre infâncias e educação das

relações étnico-raciais

\section{denuncias y pronunciaciones: estudios afro-perspectivistas sobre infancias y educación de las relaciones étnico-raciales}

\section{resumen}

El horizonte para los desafíos de este breve estudio afro-perspectivista es la articulación entre la educación de las relaciones étnico-raciales y los estudios de la infancia. Los problemas generacionales de la infancia no están disociados de la racialización. Por lo tanto, el racismo es un fenómeno que debe abordarse en los contextos infantiles. Este ensayo presenta algunas denuncias sobre situaciones de racismo que afectan a los niños/las niñas en Brasil. Además de las denuncias que son necesarias e inevitables. Este artículo-ensayo destaca lo que aquí denominamos de "pronuncias". A través de las pronunciaciones postulamos que es importante proponer caminos antirracistas. La filosofía afroperspectivista opera a través de una trama en la que la infancia, como concepto filosófico, es la clave existencial y política para la promoción de la afrotopia. Teniendo en cuenta el debate realizado por el economista senegalés Felwine Sarr, la afrotopia se considera una posibilidad real. En un enfoque afro-perspectivista, la conjetura es que necesitamos denegrir e infantilizar la vida para construir afrotopos. Un aspecto que merece destacarse es la idea de que el proyecto occidental promueve la edad adulta, lo que implica la colonización de la vida y el mundo. Nuestra hipótesis es que a través de la promoción de la infancia podemos tener las condiciones necesarias para las sociedades antirracistas. Al final del artículo-ensayo, sugerimos un estado afroperspectivista de la infancia como un indicador proactivo para promover otras realidades.

palabras claves: afroperspectividad; denuncias; étnico-racial; infancia; pronunciaciones. 
denúncias e pronúncias:

estudosafroperspectivistas sobre infâncias e educação das relações étnico-raciais

Não pode existir revelação mais profunda da alma de uma sociedade do que a maneira como ela trata as suas crianças ${ }^{2}$

Nelson Mandela

\section{breve introdução à afroperspectividade}

A epígrafe de Nelson Mandela é um dos pontos de partida mais relevantes deste breve estudo. As primeiras questões estão concentradas no tipo de sociedade que queremos. Dito de outra maneira, qual o mundo queremos habitar? A questão filosófica passa invariavelmente pela hipótese de Nelson Mandela. No seu discurso proferido em 08 de Maio de 1995, o então presidente da África do Sul quis chamar a atenção para um princípio bastante simples. Mandela conjecturou que nas sociedades mais felizes ${ }^{3}$, as crianças são tratadas com respeito e fora de padrões adultocêntricos. Nas sociedades mais cruéis, como disse o cineasta francês Jean-Luc Godard, "as crianças são prisioneiras políticas"4.

Dentro da afroperspectividade, as crianças são agentes relevantes e a infância é um conceito estratégico com implicações políticas que destaca as pronúncias, sem abrir mão das denúncias. Pois bem, é preciso situarquem lê a respeito da consistência da abordagem afroperspectivista.

Afroperspectividade é uma cosmosensação policêntrica ${ }^{5}$, uma abordagem polirracional ${ }^{6}$ que se orienta com pretensão à

\footnotetext{
2 Em 08 de Maio de 1995, Nelson Mandela proferiu o discurso intitulado ASociety's Soul na cidade de Pretoria por ocasião do Fundo da Infância. Logo no início, Mandela disse: “There can be no keener revelation of a society's soul than the way in wich it treats its children". A frase está no livro Nelson Mandela: in hisownwords publicado em 2003 e nos arquivos dos discursos de Nelson Mandela em https://atom.nelsonmandela.org/index.php/za-com-mr-t-1044 (acessado em 10 de Dezembro de 2019). Tradução do autor.

3 Por "sociedades mais felizes" podemos entender sumariamente todas que respeitam a liberdade, as diferenças e têm condições para que todas as pessoas vivam com dignidade.

${ }^{4}$ Em: https://www.incinerrante.com/textos/film-socialisme-os-fantasmas-da-alegoria, encontramos a informação de que a frase "as crianças são prisioneiras políticas" é debatida pelo filósofo francês Gilles Deleuze em Conversações após der atribuída a um programa de televisão intitulado "Seis vezes dois" (Sixfoisdeux), realizado por Jean-Luc Godard e Anne-Marie Miéville.

5Policêntrica é uma leitura crítica e dialógica baseada nas considerações da pensadora nigeriana OyeronkeOyewumi.

${ }_{6}^{6}$ Polirracional é uma menção ao recorte teórico do filósofo ugandense Dismas Masolo (2009). O conceito contrasta com a categoria de monorracional, isto é, uma ideia de que a "Razão" humana seria monolítica e dona de uma percepção unitária e exclusivista. Polirracionalidade seria justamente uma perspectiva de que a razão humana é plural, composta de "sistemas" variados e multidimensionais de racionalidades. Por exemplo, em algumas culturas, a racionalidade percebe o
} 
denúncias e pronúncias: estudos afroperspectivistas sobre infâncias e educação das relações étnico-raciais

pluriversalidade7, uma abordagem teórica e metodológica que surge no contexto das Ciências Humanas tendo como inspirações, o quilombismo de Abdias do Nascimento, a afrocentricidade na formulação de Molefi Asante e o perspectivismo ameríndio 8 pensado pela antropóloga Tânia Stolze Lima. (Noguera, 2019, p. 54$55)$.

A afroperspectividade é uma abordagem teórica, uma forma de investigação cujas bases filosóficas são estudos africanos e indígenas. Uma forma simples de compreender os estudos afroperspectivistas é tomá-lo como um modo de abordar a realidade que parte de um pressuposto bastante antigo da filosofia da África do oeste. As narrativas estão na base dos modos de pensar e agir. Para Hampaté Bâ (2010), a vida pode ser definida como um fenômeno narrativo. O poder das palavras, ou ainda, o ato de narrar é o que define boa parte da nossa percepção do mundo. Em linhas gerais, estamos narrando e percebendo o mundo entre dois extremos, modos infantis - no sentido pleno da palavra - e nas mais variadas formas adulteradas de existir.

Pois bem, a afroperspectividade é uma abordagem que pode ser entendida como uma trama filosófica que possui um cenário, tal qual um plano de imanência. Neste cenário movem-se personagens conceituais simpáticos e antipáticos. A protagonista da trama que convida quem pesquisa e interroga é a "Infância". A sua rival é a "Adultidade". Primeiro, entendemos que "a infância é o nome de um milagre" (Kohan, 2010, p. 134). Em outros termos, a infância é a possibilidade de criação do impossível, um convívio íntimo com o mistério de existir de modo que todo cotidiano pode ser entrevistado como algo extraordinário e, ainda, a dádiva brincante fora do comum se torna um fenômeno ordinário. A infância é um estado, uma maneira de perceber a realidade como se tudo estivesse acontecendo pela primeira vez. Enquanto por adultidade (Noguera; Gutman; Feitosa, 2017; Noguera; Alves, 2019) fazemos referência à falência do mistério, a adulteração das potências vitais mais genuínas.

\footnotetext{
tempo como um fluxo contínuo no sentido do futuro. Em outras, a racionalidade compreende que o tempo presente interfere no passado, tal como na cosmovisão ioruba.

7 Pluriversal é uma menção à perspectiva ontológica do pensador Mogobe Ramose. Uma formulação que se opõe à ideia de universal, argumentando que essa tese é controversa porque supõe a existência de uma perspectiva única e monolítica.

8 Perspectivismo ameríndio é uma construção teórica e metodológica feita por Tânia Stolze Lima e Eduardo Viveiros de Castro.
} 
No que consiste a afroperspectividade? A afroperspetividade é o plano de imanência da filosofia afroperspectivista. Todo plano de imanência pode ser tido como "um corte do caos e age como um crivo" (Deleuze; Guattari, 1992, p. 59). A consistência do plano de imanência está intimamente ligada à imagem do pensamento e aos elementos pré-filosóficos. "Deleuze o definira, previamente, ao mesmo tempo como horizonte e como solo" (Prado Jr., 2000, p. 308). Para fins de enegrecimento (aumento da compreensão e do entendimento), o plano de imanência como solo da produção filosófica deve ser considerado como pré-filosófico. Enquanto horizonte, o plano de imanência deve ser tomado como imagem do pensamento. Todo plano de imanência tem natureza pré-filosófica e mantém uma relação inseparável com a não-filosofia, isto é, todo plano de imanência é uma imagem do pensamento. A afroperspectividade é uma imagem do pensamento, uma maneira de estabelecer o "que significa pensar" (Deleuze; Guattari, 1992, p. 53) e como tal, um modo de reivindicar e selecionar o mais característico do pensamento: criar. Enquanto plano de imanência a afroperspectividade é "o movimento infinito ou o movimento do infinito" (Ibidem), movimento infinito de africanidades (Noguera, 2011, p. 7-8).

A afroperspectividade propõe uma maneira de pensar, a sua personagem conceitual que "nada tem a ver com uma personificação abstrata, um símbolo ou uma alegoria, pois (...) vive, (...) insiste" (Deleuze; Guattari, 1992, p. 86). A protagonista da trama afroperspectivista é a infância que habita todo ser vivente. Enquanto a adultidade é justamente a sua principal antagonista. Vale a ressalva, a infância não é um paraíso; mas uma relação genuína e autêntica com a vida. Em certa medida, o papel de uma utopia é combater a adultidade que insiste em nos fazer esquecer a infância que nos habita. De modo afroperspectivista, o racismo não deixa de ser uma maneira de adulterar a percepção do mundo, uma distorção da realidade que retira a humanidade de algumas populações humanas, o que beneficia apenas as pessoas brancas. Uma questão relevante para nosso estudo está na interrogação: como o racismo impacta as crianças negras na sociedade brasileira? A afroperspectividade reconhece que uma das missões de um pensamento engajado é denunciar politicamente tudo que adultera a experiência misteriosa da vida. $\mathrm{O}$ racismo é um projeto de asfixia letal que causa danos contínuos à potência vital que produz sonhos. Por isso, a denúncia é uma prática político-existencial. Em termos afroperspectivistas, a denúncia é um dos primeiros passos para que a alegria diante do espanto da vida não se transforme em tristeza ressentida. 
denúncias e pronúncias: estudos afroperspectivistas sobre infâncias e educação das relações étnico-raciais

\section{denúncias}

No Brasil, o racismo tem sido denunciado desde que a escravização negra começou. As fugas e inúmeros levantes são sinais disso: as pessoas negras nunca aceitaram o sistema escravista sem "negociar" e, ao mesmo tempo, entrar em colisão direta (Reis; Silva, 1989). As pessoas negras sempre foram sujeitos da denúncia, não objetos. Para além do sofrimento, o racismo sempre foi alvo de reações. Em 06 de setembro de 1770, Esperança Garcia, uma mulher que estava escravizada, escreveu uma carta para o Governador da Capitania de São José do Piauí, Gonçalo Lourenço Botelho. Esperança Garcia exigia justiça e denunciava maus tratos e a separação de seus filhos e esposo (Rosa, 2012). Ela fez algo que podemos chamar de uma petição no século XVIII, isso informa que ela, assim como outras pessoas escravizadas, sabiam ler e escrever e reivindicavam direitos. Seja no passado dos Brasis Colônia e Império, ou nas mais diversas fases da República durante períodos democráticos ou de ditadura, o Movimento Negro (MN) nunca se calou e tem denunciado insistentemente o racismo estrutural da sociedade brasileira (Almeida, 2018). O jurista Silvio Luiz de Almeida argumenta que o racismo é uma expressão estruturante do capitalismo que se constituiu através da escravização negra. De acordo com Almeida, o racismo tem um papel central na compreensão do capitalismo, o aparente dilema entre as categorias "raça" e "classe" é falso. Porque nas sociedades multirraciais e pluriétnicas, o racismo é um elemento permanente em todos os grupos sociais.

Vale mencionar que por $\mathrm{MN}$, entendemos todos os grupos socialmente organizados em qualquer nível com a agenda central de combate ao racismo. Tal como nos diz o historiador Amilcar Pereira, trata-se de do conjunto de entidades, organizações e sujeitos que "lutam contra o racismo e por melhores condições de vida para a população negra" (Pereira, 2013, p. 41). No final do século XX, com a emergência dos Estudos Sociais da Infância, ativistas do Movimento Negro que atuam no mundo acadêmico passaram a investigar o fenômeno do racismo nas infâncias. O economista Marcelo Paixão coordenou um vasto estudo sobre desigualdades raciais, trazendo à luz alguns dados relevantes para compreendermos as relações étnico-raciais na infância durante a primeira década 
do século XXI. No Relatório anual das desigualdades raciais 2009/2019 consta que "as taxas de mortalidade infantil e na infância de crianças filhas de mães pretas \& pardas são maiores do que as de mães brancas" (Paixão; Rossetto; Montovanele; Carvano, 2010, p. 30). A partir de uma análise de dados do Instituto Brasileiro de Geografia e Estatística (IBGE), uma década mais tarde a mortalidade infantil de crianças negras se mantinha superior a das brancas. De acordo com o Relatório, outro dado que caracterizou bem as desigualdades étnico-raciais está nos números de acesso às creches. $84,5 \%$ das crianças negras, isto é, pretas e pardas não frequentavam creches. Por outro lado: $79,3 \%$ das crianças brancas, sim. A dissertação de mestrado da educadora Eliane Cavalleiro defendida em 1998 se transformou num livro muito relevante para destacarmos as denúncias do racismo na infância em contexto escolar. Do silêncio do lar ao silêncio do lar ao silêncio escolar: racismo, preconceito e discriminação racial na educação infantil. Cavalleiro fez pesquisa de campo por oito meses e constatou que o silêncio em torno do racismo contribui para a submissão das crianças negras. Por um lado, a família tem o objetivo de proteger a criança e evita ao máximo possível falar do assunto. O racismo se torna um tema tabu. Por outro lado, a escola, através das professoras e toda equipe pedagógica, acaba por manter práticas racistas; e mesmo quando informadas disso, nada fazem. Daí, para a criança (negra) resta o silêncio. Para as crianças brancas, um imaginário de superioridade. Cavalleiro (2012) denuncia uma série de violências raciais cotidianas, a pesquisa constatou uma desigual distribuição de afetos. $\mathrm{O}$ estudo identificou que as professoras se mantinham distantes das crianças negras e davam mais atenção e afeto para crianças brancas (Cavalleiro, 2012, p. 74).

Pois bem, além do adultocentrismo típico que lê as crianças nas perspectivas das pessoas adultas (Sarmento, 2008), o cotidiano das crianças negras está recheado de situações diárias de tensões raciais. Não é raro que a escola seja um espaço hostil para as crianças negras. $\mathrm{O}$ assédio racial e situações aparentemente pontuais de discriminação acontecem em graus variados. Em 20 de Julho de 2012 alguns jornais publicaram a seguinte notícia: "Mãe denuncia racismo contra filha de 4 anos; aluna é xingada de "preta horrorosa'" (Estado de Minas Gerais, 2012) A denúncia da mãe 
denúncias e pronúncias: estudos afroperspectivistas sobre infâncias e educação das relações étnico-raciais

foi por conta de um parente de um garoto branco da mesma idade ter feito par com a menina numa festa julina escolar. A matéria do jornal O Estado de Minas diz:

"Quero saber por que deixaram uma negra e preta horrorosa e feia dançar quadrilha com meu neto." Foi assim, segundo o que já foi apurado pela polícia, que a avó de um aluno de uma escola infantil particular em Contagem, na Região Metropolitana de Belo Horizonte, se referiu a uma menina de 4 anos, em um caso de crime de racismo que revoltou funcionários do Centro de Educação Infantil Emília e levou a mãe da criança a denunciar a mulher à polícia. A diretora da escola foi acusada de não ter feito nada para impedir as ofensas racistas e ainda ter tentado abafar o caso. O episódio ocorreu dia 10, mas somente ontem, apoiada pela organização não governamental SOS Racismo, a mãe da menina, a atendente de marketing Fátima Viana Souza, revelou detalhes do caso. Ela só ficou sabendo das agressões à filha porque a professora Cristina Pereira Aragão, de 34 anos, que testemunhou tudo, inconformada com a situação e com a falta de ação da diretora da escola, pediu demissão e procurou a família da menina para denunciar o que ocorreu. Outra professora confirmou aos pais da criança a denúncia feita por Cristina. ${ }^{9}$

Na matéria referida, a professora da turma que relatou o caso para a família da menina vítima de racismo. Alguns dias depois da festa junina que ocorreu num sábado. "a avó do garoto, de acordo com o que consta no boletim de ocorrência policial ao qual o Estado de Minas teve acesso, invadiu a escola aos gritos querendo saber por que deixaram uma 'negra horrorosa' dançar com o neto dela"10. A menina não conseguiu dormir e nem jantar neste dia, na manhã seguinte vomitou durante a aula e ficou isolada. Até então, a família dela não tinha sequer sido informada. A diretora,do Centro de Educação Infantil Emília, Joana Reis Belvino uma mulher branca, considerou os acontecimentos normais. O sofrimento da menina pode ser mensurado? O que essa experiência informou para uma criança negra? E para as crianças brancas na sala de aula? E o silêncio da escola? A professora da turma teve a atitude de denunciar e depois, diante de comentários que naturalizavam a

\footnotetext{
9 Idem.

10 Idem.
} 
situação por parte da direção, pediu demissão. O acontecimento se tornou um caso policial e de justiça. A $3^{\text {a }}$ Delegacia de Polícia de Contagem instaurou um inquérito por injúria racial.

Porém, a escola não é o único território de opressão racial das crianças negras. Numa matéria publicada em 28 de janeiro de 2020, duas crianças gêmeas sofreram racismo dentro de uma estação de metrô. O espaço público também é território livre para discriminação.

A denúncia foi feita pela mãe das meninas, a técnica em metalúrgica Sandra Weydee, de 37 anos. O caso aconteceu no sábado (25), por volta das 18h30, na estação Rodoviária quando, segundo a mãe das meninas, um segurança chamou as meninas de "bucha 1 e bucha 2", em referência a lã de aço, usada para lavar pratos."A gente [mãe e filhas] estava no Iguatemi passeando e ia voltar para casa. Tinha três seguranças, dois negros e um branco, próximos da catraca. O branco estava de costas, quando ele virou e viu minhas filhas, ele gritou: 'Misericórdia' e eu fiquei sem entender. Aí ele completou: 'Bucha 1 e Bucha 2", disse Sandra em entrevista à TV Bahia.A mulher disse que as meninas começaram a perguntar o que era "bucha". "Elas começaram a me perguntar o que era 'bucha' e porque ele estava chamando elas assim. Uma delas é mais 'para frente' e disse para a outra: 'Ele estava falando do nosso cabelo'", lembrou a mãe das meninas que ficou sem reação após ouvir o ato de racismo e decidiu entrar no vagão do metrô, mas depois mudou de ideia e voltou para procurar o segurança. O agressor não estava mais no local, mas outro segurança falou que era "brincadeira". ${ }^{11}$

A expressão foi de "brincadeira" caracteriza bem aquilo que o jurista Adilson Moreira (2018) chama de racismo recreativo. De acordo com o livro O que é racismo recreativo?, a piada é uma maneira de reforçar a ideologia racista com uma suposta aparência de cordialidade. O que pode ser explicado também pelos argumentos de Lia Schuman em Sim, nós somos racistas: um estudo psicossocial da branquitude paulistana. A pesquisa de Schuman entrevistou pessoas brancas e constatou que os discursos reforçam o imaginário de superioridade estética, moral e intelectual (Schucman, 2014, p. 89).

Em 29/03/2017 o Portal Geledés, Instituto da Mulher Negra,noticiou o seguinte:

A semana passada fomos atingidos por uma notícia dolorosa. Numa escola de educação infantil, todas as crianças tinham seus cabelos lavados pela professora, menos a menina negra. Há dias voltando para casa sem ter o cabelo lavado, de repente não

11 Disponível em: <https:/ / www.correio24horas.com.br/noticia/nid/mae-denuncia-ato-deracismo-no-metro-contra-filhas-de-3-anos-bucha-1-e-2/> 
denúncias e pronúncias: estudos afroperspectivistas sobre infâncias e educação das relações étnico-raciais

aguentou mais e confidenciou à sua mãe: "A professora não lava meu cabelo, porque meu cabelo é duro, quero alisar o meu cabelo". E não quer mais voltar à escola. ${ }^{12}$

A mãe da menina relatou o seguinte:

“Eu não aceito, eu peço justiça porque eu não vou ficar com minha filha dentro de casa, sem ela poder ir para escola, sem ela fazer nada. Ela vê os outros, agora, ela corre. Antes não, ela conversava, ela falava, ela brincava, agora, ela não quer mais", disse Polyelle.

Mesmo diante dessas evidências de racismo, a Escola respondeu que o caso não era de discriminação racial. Ora, se não foi um caso de violência racial o que aconteceu? A diretora do Centro de Educação, Edvane Cosmo, trocou a profissional da turma e disse que era o caso de um mal-entendido. Ou seja, o racismo não foi enfrentado.

Nós vamos parar com o relato de casos. Este ensaio poderia listar centenas de casos por categorias. Racismo na escola, racismo em instituição religiosa, racismo em espaços de lazer, etc. O racismo é estrutural e cotidiano. Como já dissemos anteriormente, o MN tem sido responsável por inúmeras e importantes denúncias. Mas, para além de apontar uma série de fenômenos racistas e maus feitos que têm origem na própria dinâmica do Estado brasileiro, o MN tem sido responsável por anunciar e propor maneiras de combater o racismo. Na história do Brasil, o MN tem sido sujeito, porta-voz e agente do antirracismo (Pereira, 2013). As denúncias têm por função estabelecer que o racismo existe e politizar o debate. Não se trata de enquadrar as reclamações nas categorias de "vitimismo" e "mi-mi-mi". Uma das estratégias mais perversas do racismo é atribuir a culpa às vítimas. A expressão brasileira popular: "o próprio negro é racista" é um exemplo disso. Denunciar serve para começo de conversa. Mas, é preciso persistir no debate. Não basta denunciar. Nós precisamos apresentar propostas. Por isso, que para além das denúncias, precisamos pronunciar...

\footnotetext{
$12<$ https://www.geledes.org.br/tem-racismo-na-escola-sim-e-perguntar-criancasnegras/?gclid=Cj0KCQiAsvTxBRDkARIsAH4W_j8EBf6vB3BZ4lutRaBb3gL7Igf0gP66oVFw5wlQQfWf6eziqtsbU4aAmEQEALw_wcB>
} 
pronúncias

Cabe perguntar: como anunciar o antirracismo? Pois bem, quando o assunto diz respeito às questões étnico-raciais em interface com tema geracional da infância. Como foi dito, as denúncias são muito importantes; mas, o que aqui denominamos de pronúncias merece destaque. O educador Paulo Freire sempre chamou atenção para a necessidade de que as denúncias viessem acompanhadas de "anúncios" ou "pronúncias". De acordo com Paulo Freire, o anúncio de outro mundo precisa apagar os papéis de poucas pessoas oprimindo e de enormes contingentes humanos sendo oprimidos. O educador brasileiro propõe anunciar, isto é, pronunciar sempre que as denúncias sejam feitas.

Para mim o utópico não é o irrealizável, a utopia não é o idealismo, é a dialetização dos atos de denunciar e anunciar, o ato de denunciar a estrutura desumanizante e de anunciar a estrutura humanizante. Por esta razão, a utopia é também um compromisso histórico (...) somente podem ser proféticos os que anunciam e denunciam, comprometidos permanentemente num processo radical de transformação do mundo, para que os homens possam ser mais (Freire, 1980, p. 28).

Diante de desafios das relações étnico-raciais e geracionais, especialmente quando as questões reúnem racismo e adultocentrismo. A utopia precisa ser antirracista e valorizar a infância. Daí, a nossa hipótese é de que a utopia precisa ser negra, ser preta e enegrecer as coisas, tornar a realidade mais retinta, isto é, denegrir o mundo (Noguera, 2011). Trata-se de uma utopia que recubra vários tons denegro, ou melhor, uma utopia africana e, ao mesmo tempo, infantil no sentido que reconhece as crianças como agentes-chaves da transformação do mundo. Uma utopia que promova a infancialização da vida (Noguera; Barreto, 2018).

Pois bem, se a denúncia apresentou o fenômeno do racismo na infância; a pronúncia é utópica. Ela não pretende apenas contra-atacar e reagir ao racismo que afeta as crianças negra; mas, propor algo novo, um lugar que ainda não habitamos. Toda utopia é pretensiosa. Por isso, uma utopia capaz de reiventar um mundo sem racismo e adultocentrismo não poderia ter apenas caráter corretivo, isto é, operar através de uma lógica legalista que procura punir pessoas e instituições culpadas. A utopia pretende criar condições para que outras pessoas e outras instituições coabitem o mundo. Daí, nossa hipótese ser de uma utopia que possa denegrir e 
denúncias e pronúncias: estudos afroperspectivistas sobre infâncias e educação das relações étnico-raciais

infancializar o mundo. O que trouxe para o debate, os estudos do economista e músico senegalês Felwine Sarr. Num texto emblemático, Sarr (2019) denuncia o mito do desenvolvimento durável. O desenvolvimentismo é uma utopia (negativa) porque carreia os sonhos e esforços humanos para a exploração, depredação e dilapidação dos seres humanos, outras espécies animais e da natureza. O desenvolvimento dos países baseado no crescimento econômico e as conquistas individuais baseadas na meritocracia constituem-se como mitos.No escopo deste estudo em defesa de denegrir e infancializar o mundo, interpretamos as mais diversas críticas pós-desenvolvimentistas (Alvares, 1994; Esteva, 2009; Latouche, 2009; Sachs, 1992; Santos, 2010) como uma denúncia da utopia neoliberal que mantém dois papéis sociais básicos: de oprimir e ser uma pessoa oprimida. $\mathrm{Ou}$ ainda, como Florence Rodhain e Claude Llena (2006) definem o "mito do desenvolvimento durável", objetando que a ideologia desenvolvimentista possa entregar o que promete.O que parece com a ideia de "ecomito" desenvolvida por Felwine Sarr. Em Afrotopia, Sarr expõe que esse mito econômico do desenvolvimento produz práticas atávicas em que tudo é feito para confirmar a hipótese de que alguns princípios econômicos são leis naturais (Sarr, 2019.Nesse contexto do ecomito em que o desenvolvimento da riqueza vale mais do que as pessoas, Paulo Freire afirma que o sonho das pessoas oprimidas é ser opressora (Freire, 1999).

Para romper com esse sonho do oprimido se transformar em opressor como sinal da vitória, será preciso denegrir e infancializar o mundo. A ideia corrente de que "vencer na vida" é conquistar estabilidade econômica e vencer uma guerra de mercado acaba por diminuir a importância das coisas que não têm preço. Em termos afroperspectivistas, denunciamos a ideia de que todas as coisas possam se tornar mercadorias. A afroperspectividade conjectura que a adultidade é um modo de vida que acredita no mercado como centro gravitacional de toda a realidade. Uma sociedade racista, misógina e permeada de misérias só é materialmente possível porque existe um maneira racista, misógina e excludente de perceber e analisar o mundo. Sob o ecomito do desenvolvimentismo, a riqueza se concentra na mão de poucos. Por isso, vamos recorrer aos estudos de Sarr $(2016,2019)$, o economista 
senegalês nos fala da afrotopia. De acordo com Sarr, a afrotopia é a utopia que se realiza com base na realidade africana.

O Afrotopos é esse outro lugar da África, cujo advento precisa ser acelerado para a realização de suas auspiciosas potencialidades. Fundar uma utopia não é de modo algum se entregar a um doce devaneio, mas pensar espaços do real a serem alcançados por meio do pensamento e da ação; é discernir seus sinais e seus germes no tempo presente, a fim de fomentá-los. A Afrotopia é uma utopia ativa, que se atribui a tarefa de, na realidade africana, trazer à luz os vastos espaços do possível e fecundá-los (Sarr, 2019, p. 14).

Essa fecundação diz respeito a implementação de uma realidade baseada em territórios africanos. Vale destacar que para Sarr, o otimismo ingênuo e o pessimismo não ajudam a entender a afrotopia. Na esteira de Frantz Fanon e Aimé Césaire, Sarr nos convida a problematizar as teorias do desenvolvimento e buscar no continente africano, as pistas para um novo mundo. A utopia africana passa longe do projeto desenvolvimentista. O desenvolvimentismo parte de um axioma recusado pela afrotopia, a experiência da industrialização e crescimento econômico como o caminho do progresso. Em certa medida, a afrotopia junta-se às diversas críticas pós-desenvolvimentistas já mencionadas anteriormente. O que afrotopia e essas críticas possuem em comum está em reconhecer que o modelo civilizatório hegemônico não pretende superar a opressão.Sarr convida-nos para mergulhar em alguns conceitos-chave dos contextos africanos, a saber: ubuntu (humanidade), noflay (bem estar), tawfekh (intuinção/inteligência) e imihigo (acordo de desempenho/transformação). De acordo com Sarr, essas categorias analíticas fazem parte de um determinado projeto civilizatório que não tem o desenvolvimento como propósito final; mas, se preocupa com o bem estar de todas pessoas, preconizando um tipo de "pacto social" enquanto acordo em favor da transformação de todos para o bem estar individual e coletivo. Em outras palavras, a valorização da intuição para que a humanidade de todas pessoas possa florescer.

A afroperspectividade assume a afrotopia sarriana em todos os seus aspectos; mas, acrescenta a infanciliazação como condição ontológica para a pronúncia de uma utopia ativa. $\mathrm{O}$ motor-chave de uma pronúncia afroperspectivista está na confiança advinda da infância. A hipótese é bem simples, a raiz das coisas está no modo como a educação se relaciona com a infância. 
denúncias e pronúncias: estudos afroperspectivistas sobre infâncias e educação das

relações étnico-raciais

\section{A educação que pronuncia infância}

Em termos afroperspectivistas, o racismo faz parte de um projeto do Ocidente. Se entendermos Ocidente como a articulação entre três raízes duplas. Primeiro, a filosofia grega e o direito romano. Em segundo lugar, o pensamento judaico-cristão. Por fim, as bases políticas escritas pelo projeto da Revolução Francesa e o modelo econômico que nasceu com a Revolução Industrial. Na articulação desses elementos, a modernidade ocidental se configura como um sistema em que a razão do sujeito humano é instituída de direito sobre a natureza e, ainda mais, sobre aqueles que não professam os mesmos princípios e são "crianças", seres tão infantis que devem ser tutelados pelos que conhecem o Deus único judaico-cristão, o Estado democrático de direito e a maneira suprema de trocar mercadoria dentro do modo de produção capitalista. O filósofo Antônio Bispo dos Santos contribui para elucidar o fenômeno ocidental apresentando a cosmovisão euro-cristã.

O povo eurocristão monoteísta, por ter um Deus onipotente, onisciente e onipresente, portanto único, inatingível, desterritorializado, acima de tudo e de todos, tende a se organizar de maneira exclusivista. O povo eurocristão monoteísta, por ter um Deus onipotente, onisciente e onipresente, portanto único, inatingível, desterritorializado, acima de tudo e de todos, tende a se organizar de maneira exclusivista.

(...)

Ao frequentarmos um culto em um templo cristão monoteísta (um jurado em um fórum da justiça comum), podemos verificar todos os fiéis (cidadãos) postados verticalmente de frente ao altar (Tribuna do Júri), onde um pregador (Juiz) que possui status para falar em nome de Deus (da Justiça) fala das normas estáticas escritas na Bíblia (Código Legal), cobra dos fiéis (cidadãos) comportamentos e ações voltadas para a vontadede Deus (Justiça), avisa que Deus (Justiça) punirá os desobedientes e por fim anuncia as possíveis sentenças. Porém em nome de Deus (Justiça) abre oportunidades para que os pecadores (réus) recorram aos santos (advogados) e, através de doações generosas (honorários), interfiram perante Deus (Justiça) pela a sua salvação (absolvição). Nos terreiros dos povos pagãos politeístas (nas festas), as filhas e filhos de santo (pessoas da comunidade) se organizam circularmente no centro do terreiro (salão de festas), juntamente com a mãe ou pai de santo (animadora ou animador da festa) através de quem as deusas e deuses se manifestam, compartilhando a sabedoria da ancestralidade e a força viva da natureza, de acordo 
com a situação de cada pessoa da comunidade (Santos, 2015, p. 3839).

O Ocidente trabalha com princípios monolíticos e excludentes. A lógica da religiosidade permeia a política, a economia e os modelos educativos. Ocidente opera pela exclusão. Por isso, colonizar é o seu verbo imperativo. Isso não quer dizer que não existiram e persistem vozes dissonantes dentro da cosmovisão ocidental. As mulheres que foram queimadas vivas na Europa durante o período da inquisição e nos Estados Unidos da América, por exemplo, “as Bruxas de Salém” ameaçavam o sistema misógino ocidental. E, ainda hoje existem movimentos sociais, intelectuais e grupos políticos que tomam a palavra e agem em prol da liberdade. Porém, no Ocidente a cosmovisão hegemônica está ancorada num ecomito (Sarr, 2019, p. 24) sobre o qual a exclusão, travestida de desenvolvimento e progresso, é a regra. O mercado não pode atender todas as pessoas, as mais hábeis e inteligentes vencem empreendendo, enquanto aquelas que não se esforçam suficientemente não podem chegar ao podium. O reino dos céus é para alguns, algumas pessoas serão salvas e outras condenadas à danação eterna. A vitória nunca é de todos. $\mathrm{O}$ empate não é uma meta. Nesse contexto, educar significa superar a infância. O livro Pinóquio: as aventuras de uma marionete do italiano Carlo Collodi é um bom retrato do projeto de educação da modernidade ocidental. Na trama, Pinóquio representa uma criança. A metáfora que o define como um menino de madeira é um retrato da inumanidade da infância. Gepeto, o seu pai, faz todos os esforços para que ele estude. O que está subentendido é que a escola vai torná-lo "gente". Ele só poderá ser uma pessoa (de verdade) se aprender a dizer a "verdade". Daí, educar é um projeto de amadurecimento. Mas, não é novidade que a crise da educação esteja na sua concepção de infância como algo a ser superado. O pensador português Manuel Jacinto Sarmento faz um breve balanço de como os estudos sociais da infância deslocaram a infância de um "não-lugar" (Sarmento, 2008). A socióloga francesa Reginé Sirota foi firme ao dizer que não se deve perguntar o que uma criança vai ser quando crescer, visto que as crianças são algo e não serão somente quando crescerem (Sirota,1994). Ao mesmo tempo, inúmeras contribuições artísticas e filosóficas que valorizam a infância como algo em si mesma fazem parte dos debates do Ocidente. 
denúncias e pronúncias: estudos afroperspectivistas sobre infâncias e educação das relações étnico-raciais

(...) a infância que fala uma língua que não é compreendida; a segunda, Arte, em que o poeta Rainer M. Rilke chama a explorar implicações pedagógicas da afinidade entre infância e arte, vistas desde a lógica de um artista; trata-se da infância literal, que não encontra condições para si mesma nas instituições em que ela é recebida no contexto de uma sociedade; a terceira, Devir-criança, com Gilles Deleuze, propõe uma infância afirmativa, na forma de um conceito a-subjetivo, a-pessoal, afastado, de certo modo, de toda cronologia da infância, e das crianças; é a infância de uma outra temporalidade que interrompe na ordem do que se passa no mundo e em suas instituições; finalmente, J.-F. Lyotard, em O inumano, tira completamente a infância do seu lugar de etapa da vida e a leva a se encontrar com o inumano. É a infância que resta como fundo das outras infâncias (Kohan, 2010, p. 128)

A nossa hipótese é a de que mesmo diante de tantos esforços interessantes,o Ocidente não consegue se desvencilhar completamente desse projeto de superação da infância. Porque a modernidade ocidental consiste justamente em advogar o "progresso", a “ordem" e o “desenvolvimento". No contexto ocidental, advogar a infância como um território a ser explorado e divergir da obsessão por superá-la não é alguma coisa que se realize sem conflitos intelectuais, políticos, pedagógicos e espirituais. As ideias de desenvolvimento econômico, de evolução biológica, de progresso científico estão profundamente enraizadas no projeto civilizatório ocidental. Desenvolver, evoluir e progredir pressupõem a superação do passado, o amadurecimento e, por conseguinte, sub-repticiamente impõe à educação a tarefa de fazer com que "as crianças cresçam" - no sentido de deixarem a infância para trás.

O "desenvolvimento é, pois, uma maneira de universalizar um empreendimento que teve no Ocidente sua origem e seu grau de realização mais elevado" (Sarr, 2018, p. 21). A partir dos estudos afroperspectivistas, consideramos que o projeto do desenvolvimento é anti-infância. Portanto, dentro de um paradigma desenvolvimentista educar só pode significar a superação da infância. Nesse contexto, qualquer outra tentativa se torna mal-sucedida. As boas intenções de alforria a infância esbarram nos princípios que fazem toda pensar e todo agir ser adultizante. É numa utopia africana que a infância encontra um território de proteção. A afrotopia não pressupõe o desenvolvimento como meta e projeto de futuro. O futuro afrotópico se encontra com o passado, o que existe de mais antigo em cada um de nós, a nossa infância, tem valor supremo. Apenas a infância pode 
traduzir o milagre inesperado da dádiva diária de estarmos diante do desafio de reinventar o mundo. O passado é importante porque diz de onde partimos, sem conhecermos o passado é difícil entender o caminho que estamos fazendo. Esse é um dos sentidos de sankofa. O provérbio Akan diz: “se wowerefi na wo sankofa yenkyi" [nunca é tarde para voltar e buscar o que ficou para trás, ou, Nunca é tarde para voltar atrás e apanhar o que ficou para trás].

"Nunca é tarde para voltar atrás e apanhar o que ficou para trás". Ora, aqui interpretamos que esse passado a ser recuperado é a nossa infância. A infância não num sentido restrito, entendido como estar criança. Porém, como a condição genuína da existência. Afinal, uma leitura que identificasse "o que ficou para trás" com a infância individual seria empobrecedora (Noguera, 2019, p. 63)

O exercício educativo é um esforço de retomada. A educação pode ser entendida como exercício de manutenção da infância. O combate ao racismo e ao adultocentrismo no contexto ocidental é capenga, à medida que o projeto ocidental é caracterizado justamente por ser racista, adultocêntrico, patriarcal e misógino. As bases estão no "Progresso, Razão, Crescimento e Ordem (...) palavras-chave da episteme dos Tempos Modernos no Ocidente" (Sarr, 2019, p. 22). Sarr afirma que no "plano etimológico, desenvolver se opõe a enrolar, envolver. Trata-se de fazer crescer, de desenrolar, de desfraldar" (Sarr, 2019, p. 22). Uma afrotopia denigre e infancializa. Por isso, ela é anti-desenvolvimentista. Na educação, as bases para uma pronúncia antirracista e anti-adultocêntrica precisam considerar a infância como um estado a ser conservado, e conquistado. Agentes humanos precisam assumir a infância como maneira privilegiada de perceber e interpretar o mundo. Cabe uma história tradicional do povo iorubá que caracteriza bem o significado da infância. No artigo O poder da infância, encontramos uma reprodução do texto original da tradição oral.

Num reino ioruba, a rainha Oxum e o rei Xangô tiveram filhos gêmeos (ibejis) idênticos chamados Taiwo e Kehinde. Por razões que aqui não cabem ligadas à disputa do trono, os dois meninos foram viver com Iemanjá no reino de Orunmilá, guardião de Ifá. Iemanjá era a mãe adotiva dos ibjeis e tinha muito amor pelas duas crianças. Icu, a Morte, foi visitar a aldeia de Orunmilá e não quis mais ir embora. De modo que bodes morriam, pessoas velhas, jovens e crianças morriam, pássaros morriam, flores morriam, plantações de inhame morriam, árvores morriam, galinhas morriam. Orunmilá pediu que Icu saísse do povoado. Icu, a Morte, 
denúncias e pronúncias: estudos afroperspectivistas sobre infâncias e educação das relações étnico-raciais

disse que só sairia de alguém fosse capaz de obrigá-la a fazer algo que ela não quisesse. Com alguma pressa, Orunmilá recomendou que algumas embaixadoras e alguns embaixadores reunissem-se com Icu. Lá se foi uma comitiva munida de uma retórica capaz de convencer uma zebra a visitar uma leoa faminta. Mas, a comitiva não voltou. Então, Orunmilá enviou pequeno exército de guerreiras e guerreiros capazes de usar a espada como uma pantera negra usa suas garras. Mas, o pequeno exército não voltou. Depois que muita gente, tanto de paz e de guerra, foram levadas pela Morte, nenhuma pessoa do reino aceitava o convite de Orunmilá para pedir que Icu parasse de levar as pessoas. Sem a intervenção de alguém, a cada dia mais bichos morriam, cabritas, cabritos, vacas e bois deitavam para não levantar. Então, Orunmilá consultou Ifá (o sistema divinatório). O segredo revelado indicou que duas crianças: justamente os gêmeos Taiwo e Kehinde, os gêmeos (ibejis), deveriam ir conversar com o Icu, a Morte. Os meninos viviam para brincar e adoravam tocar um tambor dado por sua mãe Iemanjá. É preciso dizer que as duas crianças eram as mais levadas do reino. No dia seguinte ao convite de Orunmilá, Iemanjá relutou e não queria deixar que os filhos fossem encontrar a Morte. As crianças abraçaram a mãe e partiram animadas bolando um plano, elas queriam brincar com Icu. Elas foram conversar com a Morte da maneira que falavam com gente adulta: brincando, dançando e saltitando. Mas, com um detalhe importante. Taiwo e Kehinde sempre gostavam de pregar uma peça em quem não sabia que eles eram dois. Taiwo começou a tocar o tambor dançando, Icu gostou do que ouviu e se pôs a dançar ao lado da criança. Ao lado da estrada, atrás de arbustos estava Kehinde acompanhado a dupla por frestas entre folhas. Taiwo dançou, tocou, pulou, brincou e tudo isso na companhia da Morte. Um tempo depois, cansado Taiwo passou o tambor para Kehinde. Este tomou o lugar do irmão de modo discreto sem que a Morte percebesse. Ora, como Kehinde estava descansado, dançou, tocou, pulou e brincou com toda energia que tinha. Taiwo foi beber água, descansar e ficou atrás de arbustos observando a festa de seu irmão com a Morte. Taiwo cochilou e chegou a sonhar. Kehinde dançou, tocou, pulou e brincou por um tempo em que as pernas já não se aguentavam. Então, Taiwo despertou e vendo que o passo do irmão diminuía, espiou pelo arbusto e com cuidado saiu para tomar o lugar do irmão. Isso se repetiu por sete vezes, de modo que Icu já não aguentava mais. Daí, foi até a presença do rei Orunmilá e disse que tinha dançado mesmo sem querer e que por isso deixaria o reino. No dia seguinte, a celebração foi uma apoteose de tambores, sons de corda e de sopro. Taiwo e Kehinde, juntamente com todas as crianças, puseram gente adulta para dançar, incluindo Iemanjá e Orunmilá. Afinal, depois que duas crianças já tinham colocado a Morte para dançar, ninguém mais poderia resistir (Noguera, 2019, p. 132-133).

As duas crianças remetem ao estado de infância capaz de pôr a morte para dançar. O que significa essa capacidade de dar sentido à vida. Agora vale a pena 
retomar a epígrafe que abre este ensaio. “Não pode existir revelação mais profunda da alma de uma sociedade do que a maneira como ela trata as suas crianças". Pois bem, o tratamento dado as crianças pode ser o de entendê-las como o futuro, algo que será. Mas, pode ser, em termos educativos, criar as condições para que elas cresçam sem perderem a infância. Se entendermos que a infância é caracterizada por dois elementos: a capacidade de frequentar o reino da imaginação e a potência de inventar sentidos para vida como maneira de responder à inevitabilidade morte. A educação pode ter como princípio justamente investir em multiplicar as forçar infancializantes da vida, ao invés de contê-las. Mas, restaurar sempre que possível e estimular sua manutenção e expansão. Em termos afroperspectivistas, todo ato educativo deve acolher a infância e projetar o cultivo de seus poderes. Educar em favor da infância não significa um retorno a algum paraíso. Nem se trata de um projeto idealizado; mas, de uma proposta biofílica em que "a alegria é a prova dos nove" (Andrade, 2011, p. 73). O estado de infância propõe a alegria e destitui as pessoas oprimidas e opressoras do desejo de oprimir. Por uma razão simples, o desejo de oprimir está ancorado na adultidade, a corrupção da potência vital de entrar em contato com o mundo. A adultidade é um tipo de adoecimento, de mal consigo, a única alternativa passa a ser colonizar o mundo e outras vidas. No contexto ocidental, a educação é um projeto de instalação do desejo de colonização. Uma educação afroperspectivista visa infancializar a vida, descolonizar o mundo, isto é, produzir uma afrotopia.

\section{breve conclusão}

Em termos de uma breve conclusão, vale a pena retomar algumas perguntas. O que fazer diante do racismo que atinge crianças negras? O que as crianças brancas têm a ver com isso? O contexto ocidental é marcado pelo racismo como eixo estruturante. Como construir uma afrotopia? Um modo de enfrentar essa e outras questões que atravessaram esse artigo-ensaio é através de um, digamos, estatuto afroperspectivista da infância. Segue abaixo: 
denúncias e pronúncias: estudos afroperspectivistas sobre infâncias e educação das

relações étnico-raciais

Estatuto afroperspectivista da infância

Artigo I

fica decretado o direito à infância

para gente humana, gente animal e coisas

Artigo II

fica decretado o direito à infância

todo mundo deve experimentar a infância

do mesmo modo que toma banho e dorme todos os dias

a infância passa a ser questão de higiene

Artigo III

a infância faz ninhos e não deixar de voar por isso

fica decretado que as asas não se cortam

e que todas pessoasdevem ter lugar para voltar

Artigo IV

ficaobrigatório o uso do cartão de brincadeira

na imaginação, na bolsa ou na carteira

Artigo V

fica decretado que toda cidade deve obedecer

às leis do quilombo e da aldeia

Artigo VI

fica decretado que todo mundo

tem direito à uma história antes de dormir

referências

ALMEIDA, Silvio Luiz de. O que é racismo estrutural? Belo Horizonte: Letramento, 2018

ALVARES, Claude. Science, development and violence: The revolt against modernity. Oxford \& Nova Deli: Oxford University Press, 1994.

ANDRADE, Oswald de. A utopia antropofágica. São Paulo: Globo, 2011

BÂ, Amadou Hampaté. "A Tradição Viva". In. KI-ZERBO, J. (Org.). História Geral da África I: metodologia e pré-história da África. 2. ed. rev. Brasília: UNESCO, 2010.

CAVALLEIRO, Eliane dos Santos. Do silêncio do lar ao silêncio escolar: racismo, preconceito e discriminação na educação infantil. 6. ed. São Paulo: Contexto, 2012

DELEUZE, G.; GUATTARI, F. O que é a filosofia? Trad. Bento Prado Jr. e Alberto Alonso Muñoz. Rio de Janeiro: Editora 34, 1992.

ESTEVA, Gustavo. "Más allá del desarrollo: La buena vida". América Latina en Movimiento, 445, pp. 1-5, 2009 
Mãe denuncia racismo contra filha de 4 anos; aluna é xingada de "preta horrorosa" Jornal Estado de Minas, Minas Gerais, 20/07/2012. Disponível em: <https://www.em.com.br/app/noticia/gerais/2012/07/20/interna_gerais,30710 9/mae-denuncia-racismo-contra-filha-de-4-anos-aluna-e-xingada-de-pretahorrorosa.shtml $\geq$ Acesso em 08/09/2019.

FREIRE, Paulo. Conscientização: teoria e prática da libertação. $3^{\text {a }}$ Ed. São Paulo: Moraes, 1980. FREIRE, Paulo. Educação como prática da liberdade. 23a ed. Rio de Janeiro: Paz e Terra, 1999. KOHAN, Walter. "Vida e Morte da Infância, entre o Humano e o Inumano" .Educ. Real., Porto Alegre, v. 35, n. 3, set./dez., 2010, p.125-138

LATOUCHE, Serge. Sobrevivir al desarrollo: De la descolonización del imaginario económico a la construcción de una sociedad alternativa (2a ed.). Barcelona: Icaria, 2009.

MASOLO, Dismas. "Filosofia e conhecimento indígena: uma perspectiva africana" In SANTOS, Boaventura Sousa; MENESES, Maria Paula. Epistemologias do sul (org). Coimbra: Almedina, 2009.

MOREIRA, Adilson. O que é racismo recreativo? Belo Horizonte: Letramento, 20

18.

NOGUERA, Renato. “'Antes de saber para onde vai, é preciso saber quem você é': tecnologia griot, filosofia e educação" Problemata: R. Intern. Fil. V. 10. n. 2 (2019A), p. 258-277

NOGUERA, Renato. "Denegrindo a filosofia: o pensamento como coreografia de conceitos afroperspectivistas". In Griot - Revista de Filosofia, Amargosa, Bahia - Brasil, v.4, n.2, dezembro/2011, pp. 1-19.

NOGUERA, Renato. "Infância em afroperspectiva: articulações entre sankofa, ndaw e terrixistir" Revista Sul-Americana de Filosofia e Educação - RESAFE, n.31, mai-out 2019B, pp.53-70

NOGERA, Renato; ALVES, Luciana. "Infâncias Diante do Racismo: teses para um bom combate". Educação \& Realidade, Porto Alegre, v. 44, n. 2, 2019

NOGUERA, Renato; BARRETO, Marcos. "Infancialização, Ubuntu e Teko Porã: elementos gerais para educação e ética afroperspectivistas". Childhood \& Philosophy, Rio de Janeiro, v. 14, n. 31, p. 625-644, set.-dez. 2018

NOGUERA, Renato; GUTMAN, Catia; FEITOSA, Dayane. "Pintando e desenhando Pinóquio e Kiriku na escola". Aprender: caderno de Filosofia e Psicologia da Educação. Vitória da Conquista-BA, Ano XI, n. 19, p. 75-94, jul./dez. 2017

PAIXÃO, Marcelo; ROSSETTO, Irene; MONTOVANALE, Fabiana; CARVANO, Luiz Marcelo (organizadores) Relatório Anual das Desigualdades Raciais no Brasil; 20092010: Constituição Cidadã, seguridade social e seus efeitos sobre as assimetrias de cor ou raça. Rio de Janeiro: Garamond Editora, 2010.

PEREIRA, Amílcar Araújo. O mundo negro: relações raciais e a constituição do movimento negro contemporâneo no Brasil. Rio de Janeiro, Pallas/Faperj, 2013.

REIS, João José e SILVA, Eduardo. Negociações e Conflito; a resistência negra no Brasil escravista. São Paulo: Companhia das Letras, 1989.

RODHAIN, Florence; LLENA, Claude. "Le mythe du développement durable" Préventique Sécurité. Janvier-février 2006 - 47 N85, pp.41-47.

ROSA, Sonia. Quando a escrava Esperança Garcia escreveu uma carta. Ilustração Luciana J. Hees. Rio de Janeiro: Pallas, 2012.

SACHS, Wolfgang (Org.). The development dictionary: A guide to knowledge as power. Londres \& Nova Iorque: Zed Books, 1992.

SANTOS, Antônio Bispo. Colonização, Quilombos. Modos e Significações. Brasília: Instituto de Inclusão no Ensino Superior e na Pesquisa, 2015. 
denúncias e pronúncias: estudos afroperspectivistas sobre infâncias e educação das relações étnico-raciais

SANTOS, Boaventura Sousa. "Para além do pensamento abissal: Das linhas globais a uma ecologia dos saberes". In SANTOS, Boaventura\& MENESES, Maira Paula (Orgs.), Epistemologias do Sul. Coimbra: Almedina/CES, 2010, p.23-71.

SARMENTO, Manuel Jacinto. "Sociologia da Infância: Correntes e Confluências" In SARMENTO, Manuel Jacinto e GOUVÊA, Maria Cristina Soares de (org.) Estudos da Infância: educação e práticas sociais. Petrópolis. Vozes, p.17-39, 2008.

SARR, Felwine. Afrotopia. Tradução Brasil: n-1 edições, 2019.

SARR, Felwine. "Développement: toute une terminologie à revoir". Brenn punkt Drëtt Welt, 296, pp. 7-9, 2016

SCHUMAN, Lia V. "Sim, nós somos racistas: um estudo psicossocial da branquitude paulistana" Psicologia \& Sociedade, 26 (1), pp.83-94.

SIROTA, Regine. "L'enfant dans la sociologie de l'éducation: un fantôme ressuscité?" Revue de L'Institut de Sociologie. Université Livre de Bruxelles. 1994, p. 147-163.

recebido em: 16.02 .2020

aprovado em: 21.06 .2020 